\title{
Coping with Favoritism in Recruitment and Selection: A Communal Perspective
}

\author{
Jasper Hotho ${ }^{1}$. Dana Minbaeva ${ }^{2} \cdot$ Maral Muratbekova-Touron $^{3} \cdot$ Larissa Rabbiosi $^{2}$
}

Received: 4 May 2017 / Accepted: 19 December 2018 / Published online: 22 December 2018

(c) The Author(s) 2018

\begin{abstract}
We examine how recruiting managers cope with communal norms and expectations of favoritism during recruitment and selection processes. Combining insights from institutional theory and network research, we develop a communal perspective on favoritism that presents favoritism as a social expectation to be managed. We subsequently hypothesize that the communal ties between job applicants and managers affect the strategies that managers employ to cope with this expectation. We test these ideas using a factorial survey of the effects of clan ties on recruitment and selection processes in Kazakhstan. The results confirm communal ties as antecedents to the strategies managers use to cope with communal favoritism. Surprisingly, the results also show that these coping strategies are relatively decoupled from managers' recruitment decisions. The findings contribute to favoritism research by drawing attention to the mitigating work of managers in societies in which favoritism is common.
\end{abstract}

Keywords Business ethics · Communities · Favoritism · Human resource management · Institutional logics · Recruitment and selection

As soon as you are doing better than others, as soon as you have even a small amount of money, you should help everyone around you. Everybody should help everybody.

-Study participant.

Jasper Hotho

jh.egb@cbs.dk

Dana Minbaeva

dm.si@cbs.dk

Maral Muratbekova-Touron

mmuratbekova@escpeurope.eu

Larissa Rabbiosi

lr.si@cbs.dk

1 Department of International Economics, Government and Business, Copenhagen Business School, Frederiksberg, Denmark

2 Department of Strategy and Innovation, Copenhagen Business School, Frederiksberg, Denmark

3 Department of Strategy, Organizational Behavior and Human Resources, ESCP Europe, Paris, France

\section{Introduction}

Favoritism in recruitment and selection remains a persistent challenge in societies where the effects of globalization are on the rise. Due to the rapid professionalization of local workplaces, managers in these societies are now commonly expected to base recruitment decisions exclusively on candidates' qualifications and merit (Stahl et al. 2012). Yet, these same managers often remain firmly embedded in local communities in which obligations still feature prominently (Oyserman et al. 1998). While managers' embeddedness in local communities can provide recruitment-related benefits (Horak 2016; Jones and Stout 2015), the norms and obligations of these communities typically exert considerable pressure on recruiting managers to diverge from professional standards and engage in various forms of favoritism (Begley et al. 2010; Chen et al. 2015). As a result, managers responsible for recruitment processes that involve applicants from their own communities frequently face the acute, practical challenge of reconciling conflicting sets of social expectations regarding the recruitment process.

In this study, we aim to advance our understanding of how managers attempt to resolve this dilemma, and how they cope with communal norms of favoritism in their daily work. 
To this end, we propose and test a communal perspective on favoritism which builds on insights from organizational institutionalism on institutional logics and social cues (DiMaggio 1997; Thornton et al. 2012; Weber and Glynn 2006). The perspective we develop is novel in that it emphasizes the obligations embedded in managers' communities as an important source of normative pressure to engage in favoritism in recruitment and selection. Specifically, we theorize that exposure to community members provides recruiting managers with social cues that invoke the norms and obligations embedded in communities, including expectations of favoritism in recruitment. Drawing on insights from network studies, we then propose that the characteristics of recruiting managers' social ties with job applicants from their community - especially, the levels of immediacy and relatedness-will affect how managers cope with expectations of favoritism during recruitment and selection processes. We test these ideas using a factorial survey-a quasi-experimental research design-focused on the relationship between social ties and the coping strategies of recruiting managers in Kazakhstan.

Our intended contribution is twofold. First, we aim to complement recent research on managerial attitudes towards favoritism in recruitment with insights into how recruiting managers practically cope with pressures to engage in favoritism in their daily work. Attitudinal studies have significantly extended our understanding of how managers perceive favoritism, and why (Chen et al. 2015), as well as managers' tolerance of such behavior in others (Wated and Sanchez 2015). In contrast, less is known about how managers attempt to resolve the practical dilemmas that arise in work contexts where different norms towards favoritism prevail. By studying the practical strategies managers use to handle such situations, we seek to add to a deeper understanding of the role and influence of managers in societies in which favoritism is widespread.

Second, we aim to contribute to favoritism research by drawing attention to the local networks in which managers are embedded. Favoritism research has invested much effort into understanding culture as a source of favoritism and of individuals' attitudes towards it (Chen et al. 2015; Khatri and Tsang 2003; Wated and Sanchez 2015). Considerably less attention has thus far been dedicated to the networks of managers and the ties they hold with potential job candidates. By focusing on the communal ties between recruiting managers and job applicants, we hope to add insights into when and how managers may experience social pressure to engage in favoritism, and the effects of that pressure on their daily handling of recruitment processes. Such insights are relevant for both public and private attempts to combat favoritism in recruitment and selection.

In the following sections, we first develop our communal perspective on favoritism. We do this by highlighting communities and communal obligations as an important source of normative pressure towards favoritism in recruitment and selection processes. We subsequently theorize that the structural attributes of the communal ties between managers and job candidates will affect how managers handle the social pressure to engage in favoritism during recruitment and selection processes. We discuss our research design and present the results of our factorial survey. The paper ends with a discussion of the contributions of our study to favoritism research and beyond.

\section{Favoritism in Recruitment and Selection}

Favoritism in recruitment and selection-defined as recruitment, appraisal, and promotion on the basis of connections rather than merit (Prendergast and Topel 1996) represents an ethically charged class of management practices. Favoritism is generally considered to be unethical because of its association with a range of negative side effects. These include discrimination, corruption, the loss of productivity, reduced job satisfaction, increased inertia, and stress (Khatri and Tsang 2003; Pearce 2015; Pearce et al. 2000). However, the ethical status of favoritism is not uncontested. Some point out that favoritism forms an inherent part of indigenous management practices that are widely accepted and used in their local contexts (McCarthy et al. 2012). Examples are the notions of blat in Russia (Ledeneva 1998), guanxi in China (Dunfee and Warren 2001; Warren et al. 2004), clanism in Kazakhstan (Minbaeva and Muratbekova-Touron 2013), jeitinho in Brazil (Tanure and Duarte 2005), jaan-pehchaan in India (McCarthy et al. 2012), and yongo in Korea (Horak 2016, 2017). Others highlight that there are circumstances in which favoritism leaves individuals and organizations better off, not worse (Jones and Stout 2015). For example, Horak (2016) argues that for small and medium-sized Korean firms, the use of favoritism may lead to more widely accepted, reliable, and efficient recruitment results. The necessity and prevalence of favoritism in many societies makes some consider favoritism ethical and acceptable in these contexts (McCarthy et al. 2012).

Favoritism and its various manifestations, such as nepotism and cronyism, are frequently explained in terms of cultural norms and values. For example, Khatri and Tsang (2003) link favoritism in superior-subordinate relationships to the cultural dimensions of particularism and paternalism. Wated and Sanchez (2015) show that Ecuadorean managers' tolerance of employees who engage in nepotism is affected by the degree of collectivism and prevailing norms. Chen et al. (2015) demonstrate that particularism has a surprisingly negative effect on whether managers perceive favoritism in promotion decisions as fair. 
Recent work indicates that the effects of culture on favoritism may be mediated by the social structures in which individuals and organizations are embedded (Liu et al. 2015; Skilton 2008). For example, Begley et al. (2010) suggest that the prevalence of cronyism varies with the type of network competition, and with whether networks are tight or loose. Liu et al. (2015) show that the presence of strong ties may reinforce nepotism within family firms because they create a sampling bias. This renewed emphasis on social structures opens favoritism research up to a range of new, exciting questions. We see three areas as particularly important research avenues.

First, while favoritism research has paid a considerable amount of attention to culture as a source of favoritism (e.g., Al-Aiban and Pearce 1993; Khatri and Tsang 2003) and to attitudes towards favoritism (e.g., Chen et al. 2015; Wated and Sanchez 2015), it has been less attentive to how social structures may serve as sources of favoritism in their own right. An illustration of the latter are the helping behaviors and favoritism observed within geographical and virtual communities (e.g., Wasko and Faraj 2000; Wellman and Wortley 1990). Such behaviors often appear to stem at least as much from communal norms as from cultural values. Paying closer attention to social structures may enable favoritism research to paint a more differentiated picture of the sources of favoritism and its occurrence.

Second, while extant research has sought to establish links between the prevalence of favoritism and network characteristics (e.g., Begley et al. 2010), we believe it is important to complement such studies with research on the effects of the specific ties that constitute those networks. Such studies have the potential to refine our understanding of favoritism and its effects in two ways. First, by paying more attention to network ties, favoritism research can explore the effects of different degrees of closeness (Chen et al. 2015). Second, paying attention to the varied nature of network ties, especially indirect ties, serves as a reminder that two individuals might be affected by local favoritism norms even in the absence of direct ties between them.

Finally, favoritism research has paid surprisingly little attention to the individuals who handle recruitment and selection processes. This lack of attention to the role of individuals is problematic because the effects of cultural values and communal norms on recruitment decisions are ultimately mediated by the individuals who occupy recruitment functions. While recent studies significantly advance our understanding of attitudes towards favoritism in recruitment and selection (Chen et al. 2015; Wated and Sanchez 2015), attitudes do not always equate with action. In fact, in some cases, recruiting managers may play an essential mitigating role in limiting the effect of social expectations on recruitment and selection decisions. However, we still lack insights into how managers experience social pressures to engage in favoritism and the varied ways in which they cope with such expectations in their handling of selection processes. As a result, we may routinely underestimate the essential mitigating work that managers undertake to counter favoritism in organizations.

\section{Towards a Communal Perspective on Favoritism}

Our interest in this paper is in understanding how recruiting managers handle the acute, practical dilemma that arises when they are exposed to conflicting expectations from their workplace and community regarding how a recruitment process should unfold. To this end, we combine insights from organizational institutionalism and network studies to develop a communal perspective on favoritism. Insights from organizational institutionalism are helpful because this strand of institutional theory is sensitive to the fact that the behaviors of individuals are subject to broader societal and communal norms, as well as the fact that these may pose conflicting demands (e.g., Currie and Spyridonidis 2016; Giorgi and Palmisano 2017; Pache and Santos 2013; Smets et al. 2015; Thornton et al. 2012). Specifically, we first draw on insights from organizational institutionalism regarding institutional logics and social cues (DiMaggio 1997; Thornton et al. 2012; Weber and Glynn 2006) to develop theory about when and how recruiting managers experience communal norms towards favoritism during recruitment and selection processes. We use insights from this stream of literature to suggest that workplace exposure to community members may provide social cues that invoke the obligations, identities, and repertoires of action embedded in that community. We subsequently draw on network studies to propose that attributes of social ties with community members-especially the levels of immediacy and relatednessaffect how communal norms of favoritism are handled during recruitment processes.

\section{Communities and Social Obligations}

Institutional logics are the dominant frames of reference that shape rational, mindful behavior in a social context (Thornton and Ocasio 2008). Institutional logics build on interrelated sets of symbolic meaning systems and material practices that are rooted in specific social domains, such as the family, religion, or the market (Friedland and Alford 1991). As a result, the institutional logics from different social domains can provide conflicting and incompatible rationales for decision making and identity construction (Thornton et al. 2012). For instance, many contemporary workplaces are characterized by an economic rationality that emphasizes profit maximization and professional expertise (Almandoz 
2012; Thornton 2001, 2004). This market logic directs the attention of managers and employees towards resource competition and competitiveness, and tends to promote relations that are relatively impersonal (Thornton and Ocasio 1999; Thornton et al. 2012). In contrast, communities are institutional orders that center on meaningful and affective relationships (Marquis et al. 2011; Thornton et al. 2012). Brint (2001, p. 8) defines communities as "aggregates of people who share common activities and/or beliefs and who are bound together principally by relations of affect, loyalty, common values, and/or personal concern." Although communities are often closely linked to particular geographical areas, such as neighborhoods or regions, online communities illustrate that physical proximity is not required for community ties and obligations to develop (Wasko and Faraj 2000).

Whereas personal obligations are often bilateral, communal obligations stem from an internalized sense of responsibility to members of a community. Communal in-group perceptions activate relational schemas, which evoke a generalized sense of obligation and responsibility (Baldwin 1992; Oyserman et al. 1998; Triandis 1995). As a result, within communities, reciprocities are generalized beyond specific individuals to community members in general (Ekeh 1974; Gouldner 1960; Westphal and Zajac 1997). An illustration of this is found in the work of Muir and Weinstein (1962), who show how generalized communal obligations encourage altruism and gift giving in lower-class communities. In communities, social obligations therefore extend beyond close personal contacts and relations, and beyond those to whom one is indebted, to members of the community with whom one may not be personally acquainted. Such generalized reciprocities contribute to the sense that we "often feel bound by our obligations to others. We regularly commit time, effort, and tangible resources in an attempt to respond to others' needs. We even engage in these helping behaviors in spite of considerable personal inconvenience or hardship, largely because we believe we should" (JanoffBulman and Leggatt 2002, p. 260).

\section{Community Obligations and Social Ties}

Management research increasingly recognizes the relevance of the communities in which individuals and organizations are embedded (Marquis and Battilana 2009; Smets et al. 2015). However, there has been little discussion of what drives individuals to act on community logics and communal obligations in work situations. The logics literature discusses how socialization may familiarize individuals with an institutional logic (Pache and Santos 2013), and how logics shape individuals' actions and interactions (Thornton et al. 2012). Drawing on insights from the literature on social cues (DiMaggio 1997; Gould 1995), we suggest that the reverse may also be true-social interactions and exposure may evoke the social identities, goals, and attention patterns of institutional logics, including community logics and the obligations embedded in them.

The social cues literature highlights that interactions with network members serve as contextual cues that activate the "schemata, logics and frames" embedded in local networks (DiMaggio 1997, p. 283). When interactions take place in a certain context, such as when we meet colleagues at work or family members at home, the logics evoked by those interactions are largely congruent with the situational context, and are likely to reinforce expected identities and action frames (Weber and Glynn 2006). However, when exposure is out of context and individuals associated with one sphere of life are encountered in another, logics can be activated that differ from and potentially conflict with the situational logic of the context in which the encounter takes place. In recruitment and selection processes, therefore, we expect exposure to community members in work situations to provide social cues that invoke the interests, obligations, identities, and repertoires of action embedded in that community.

We use this insight to understand how managers experience and handle communal norms of favoritism during recruitment and selection processes. Specifically, in the following sections, we draw on insights from social network studies to highlight how the structural attributes of social ties with community members affect managers' experience of communal norms. We distinguish between the immediacy of social ties, or the structural distance to community members, and qualitative differences in social ties in terms of the relatedness of community members. These attributes are important because they affect the degree and permanence of the obligations managers feel towards community members. As we discuss in the next section, we expect these attributes to affect how managers handle communal norms of favoritism during recruitment and selection processes.

\section{Immediacy}

One factor likely to affect how managers experience and handle communal norms and obligations lies in the structural distance to community members, especially the immediacy of the tie. In social network analyses, immediacy is commonly captured by distinguishing between direct and indirect ties. Direct ties are direct personal relationships among members of a network (Burt 1987). Indirect ties, in contrast, are relationships among network members that are mediated by other ties (Ahuja 2000; Bian 1997; Shane and Cable 2002). The notion of indirect ties highlights the fact that community members are connected to other community members even in the absence of direct ties.

The distinction between direct and indirect ties matters because it affects the degree of obligation experienced towards community members. Compared with indirect ties, 
direct ties are more intimate and affective (Granovetter 1973; Marsden and Campbell 1984), and they encourage greater reciprocity and trust (Shane and Cable 2002). Managers are therefore likely to experience stronger obligations and responsibilities towards community members with whom they have a direct tie than towards community members with whom they have an indirect tie.

Immediacy also affects the enforcement of social norms and the threat of social sanctions (Brint 2001). The presence of a direct tie makes it possible to remind others of shared norms and obligations, to signal discontent, and to engage in forms of social punishment that can inflict significant social and emotional damage (Bastian and Haslam 2010), such as the withdrawal of support or the severing of social ties (Feldman 1984; Wiessner 2005). When ties are indirect, sanctions are likely to involve forms of reputational punishment, such as shaming and ridiculing, which require greater social coordination, are less immediate, and are less predictable in their outcomes (Posner and Rasmusen 1999). Therefore, while community members may feel a general sense of obligation to all community members, the obligation that individuals feel and their propensity to align their behaviors with community expectations are likely to be higher in the presence of direct ties than in the presence of indirect ties.

\section{Relatedness}

The obligations embedded in communal ties are also affected by whether two individuals are related. As work in social anthropology shows, the distinction between community members who are related and those who are not captures an important qualitative difference in the permanence of social obligations. As Boissevain (1966) highlights in his study on social obligation in Sicily:

An individual is born into a kinship system, and there finds, ready-made so to speak, a network of persons with whom he has a series of jurally defined obligations. ... In contrast, ... the relation between patron and client, or between friends, is entered into voluntarily (Boissevain 1966, pp. 21-22).

The permanence and immutability of the obligations embedded in family and kinship ties mean that such ties constitute a valuable and trusted resource for informal exchange and the provision of public goods (Cox and Fafchamps 2007; Schweizer and White 1998; White 2011). For example, kinship ties encourage risk and opportunity sharing (Rosenzweig 1988), such as the sharing of information on work and business opportunities (Granovetter 1995a, b). The permanence of kinship ties also facilitates the pooling of resources to support business activities (Krishnan and Sciubba 2009; Wade 1988).
Relatedness is often taken to refer to "true" or biological kin relations in which individuals are connected to relatives through consanguineal ties (Engels 1942; Sudarkasa 1998). However, in many communities, the notion of relatedness includes "fictive" kin relations with individuals who are regarded in kinship terms even though they are unrelated by blood or marriage (Pitt-Rivers 1973). Irrespective of whether kinship relations are fictive or real, the fact that someone is considered related results in a qualitative change in rights, status, and obligations. For example, in their study of fictive kinship relations in black communities in the US, Chatters et al. (1994, p. 297) note that "friendships which are regarded in kinship terms undergo an intensification of the bonds of mutual obligation in what normally would be a relatively informal and casual relationship." Cha (2000) notes that, as in other Asian societies, social groups in Korea are often characterized by forms of pseudo-familism that encompass levels of dedication and obedience similar to those found in biological kinship relations.

Such examples illustrate that although communities differ in who is considered related, in most communities the notion of relatedness implies immutable obligations and trust. This is important for the purpose of our study because it suggests that relatedness is likely to affect how individuals respond to social expectations of favoritism during recruitment and selection processes.

\section{Hypothesis Development}

In hypothesizing about how managers cope with communal norms of favoritism during recruitment and selection processes, we build on insights from the literature on institutional complexity. While much of this literature is concerned with organizations (e.g., Battilana and Dorado 2010; Greenwood et al. 2011; Marquis and Lounsbury 2007; Pache and Santos 2010), it has increasingly paid attention to individuals. In so doing, this stream of literature demonstrates that individuals draw on a range of responses when faced with conflicting expectations from important referent audiences. For example, recent work shows that when individuals are confronted with conflicting demands, they may seek to delay decision making (Holm et al. 2017; Raaijmakers et al. 2015), or attempt to compartmentalize (Pache and Santos 2013), blend (Currie and Spyridonidis 2016), or balance those demands (Smets et al. 2015). Other work shows that individuals may engage in identity work to reconcile institutional contradictions (Creed et al. 2010).

For the purpose of our study, such research suggests that recruiting managers may employ a range of strategies to partially satisfy and comply with communal norms during recruitment processes. Nevertheless, it is noteworthy that in the professional context we study, managers are presented 
with an acute dilemma which demands a fairly immediate professional response: Job applications need to be handled, and recruitment-related practices need to be selected. This condition precludes cognitive coping strategies, such as identity work, or strategies that are overly time-dependent. We therefore draw on Oliver's (1991) framework of behavioral responses to institutional pressures. Hence, we expect managers to engage in practices that signal compliance (acquiescence) or passive conformity (compromise) with communal norms of favoritism, as well as practices that serve to avoid or even defy those norms.

In the following, we develop hypotheses on how the degree of relatedness and the immediacy of communal ties with job candidates affect managers' handling of recruitment and selection processes. In other words, rather than focus on the effects of communal ties on the outcomes of selection and recruitment processes, we investigate the coping strategies that recruiting managers employ to handle communal norms in their daily work.

\section{Coping with Communal Favoritism in Recruitment and Selection}

As discussed above, an important difference between ties with related community members and ties with unrelated community members is that the former are more permanent. Therefore, the obligations embedded in ties with related community members are perceived as more binding and the implications of not fulfilling them are viewed as more enduring. As Bott (1971, p. 295) highlights in a study of the social and psychological organization of urban families:

Kin are of special importance in any type of network.

... First, kin are especially likely to know one another, so that the kinship region of the network is likely to be more close-knit than other sectors. Second, relationships with and among close kin are relatively permanent.

The permanence of kinship relations and the obligations embedded in them imply that managers exposed to related job applicants should be more inclined to align their handling of the recruitment process with communal norms of favoritism than to engage in behaviors that challenge or question those norms. One example of alignment with such communal norms would be to limit the use of assessment tools when assessing an applicant. In addition, we expect the immediacy of a tie to affect managers' efforts to comply with communal norms of favoritism. As with direct ties more generally (Burt 1987; Granovetter 1973), individuals are more likely to develop affective relations with relatives with whom they are in contact and they are more likely to feel obliged to help them. Although people may regard helping behaviors as a burden, such behaviors reflect and reinforce individuals' social ties to others and, ultimately, lead to more binding relations (Janoff-Bulman and Leggatt 2002). The intimacy of direct ties with relatives also enables and enhances the threat of social sanctions, such as shunning or disapproval. Therefore, if a tie with a job applicant is direct and the applicant is related, we expect recruiting managers to align their handling of the recruitment process with communal norms and expectations of favoritism.

In contrast, if a job applicant is related but the tie is indirect, as might occur with more distant family members, we expect managers to be inclined to adopt a more balanced approach to communal norms and expectations. Although social ties with relatives are permanent, the lower attachment associated with non-immediate ties coupled with the lower threat of social norm enforcement should make managers less willing to lose sight of their own interests. In other words, we expect managers to be inclined to balance the expectations of the community with their own professional interests, and to engage in practices and behaviors that are perceived as legitimate in the workplace. Therefore, when a job applicant is related but the tie is indirect, we expect managers to pursue a compromise strategy, such that they handle the recruitment process in ways that accommodate communal norms of favoritism but only partially conform with them. Hence, we propose:

Hypothesis $1(\mathrm{H} 1)$ When a job applicant is related and directly connected to a recruiting manager, that manager is likely to seek alignment with communal norms by employing an acquiescence strategy during the recruitment process.

Hypothesis $2(\mathrm{H} 2)$ When a job applicant is related but indirectly connected to a recruiting manager, that manager is likely to balance communal obligations and professional interests by employing a compromise strategy during the recruitment process.

In contrast, when a job applicant is unrelated, social obligations are more fluid and the implications of non-conformity are less enduring. Under such conditions, the lower permanence of social obligations enhances the likelihood that managers will seek to serve their own interests by adhering to behaviors that are sanctioned by the work environment. Nonetheless, if a job applicant is unrelated but maintains a direct tie to the recruiting manager, we suggest that the emotional attachment embedded in that tie may entice the manager to engage in efforts to conceal non-conformity, or to engage in the "window dressing', ritualism, ceremonial pretense or symbolic acceptance" (Oliver 1991, pp. 154-155) of community obligations. In such instances, we expect recruiting managers to attempt to preclude or avoid the necessity of aligning their behavior with community obligations. 
If, however, the communal tie to an unrelated job candidate is indirect, as with a community member with whom a manager is unfamiliar, we believe the fluidity of obligations and low emotional attachment will provide the manager with sufficient leeway to engage in behaviors that defy or reject community obligations. In such situations, individuals are likely to feel little obligation to deviate from the situational logic in their workplace when handling a recruitment process. Furthermore, given their limited attachment, recruiting managers should have little motivation or need to engage in efforts to avoid or conceal non-compliant behavior. Thus, in situations where relatedness is low and communal ties are indirect, defiance is the likely strategic response because the ties are neither relational nor affective, and individuals "have little to lose by displaying their antagonism towards the constituents that judge or oppose them" (Oliver 1991, p. 157). Hence, we propose:

Hypothesis $3(\mathrm{H} 3)$ When a job applicant is unrelated but directly connected to a recruiting manager, that manager is likely to conceal non-conformity by employing an avoidance strategy during the recruitment process.

Hypothesis $4 \mathbf{( H 4 )}$ When a job applicant is unrelated and indirectly connected to a recruiting manager, that manager is likely to reject communal norms and employ a defiance strategy during the recruitment process.

\section{Methods}

\section{Context of the Study: Clanism in Kazakhstan}

Kazakhstan is a clan-based society, which provides a natural empirical setting for studying how the attributes of communal ties affect the way managers cope with communal norms of favoritism during recruitment processes. Clans are social systems that are characterized by a community logic that emphasizes non-dyadic and non-reciprocal (or generalized) obligations towards known and unknown members of the network (Collins 2006; Schatz 2004, 2005). Although clan structures exist in many non-western economies (Schweizer and White 1998), the resilience and power of clan structures are particular to Central Asia, especially to Kazakhstan, and they are derived from the nomadic origins of these societies (Schatz 2004; Collins 2006). Despite explicit policies to eradicate local clan structures during Soviet rule, kinship ties survived and were reinforced as effective, trusted informal channels, and they continue to serve as identifiable mechanisms of identity reproduction (Schatz 2004).

Historically, clan affiliations in Kazakhstan were defined in terms of familial and communal ties (Schatz 2004, 2005). In modern Kazakhstan, clan affiliations are based on a wider variety of ties, and they include ties with direct relatives and extended family, affinal ties (by marriage), and ties reflecting commonalities in geographical origins, schooling, or family friendships (zemlyaki) (Minbaeva and Muratbekova-Touron 2013). Nevertheless, true kinship ties remain central in Kazakhstan-individuals are expected to be able to recount their genealogy for the past seven generations (zheti ata), and to be able to list both clan ( $r u$ ) and umbrella-clan (zhuz) affiliations (Minbaeva and Muratbekova-Touron 2013). ${ }^{1}$

Another advantage of this focal context is that Kazakhstan has experienced an influx of Western management practices that, in line with market logics, dictate hiring and selection on the basis of qualification and merit (Minbaeva et al. 2007). Managers are therefore expected to develop and implement transparent, formalized, and standardized recruitment and selection practices. However, Kazakhstan's transition process also implies that formal institutions are often weak and incomplete. As a result, clan relations and obligations are often perceived as having continued relevance in the allocation of positions and resources (Collins 2006; Minbaeva and Muratbekova-Touron 2013).

\section{Factorial Surveys}

To test our hypotheses, we collected data through a factorial survey. In contrast to regular surveys, factorial surveys introduce an element of experimental design. Participants are provided with standardized, randomly assigned situational descriptions - short stories known as "vignettes"which incorporate factors relevant to the study. Participants are then presented with questions related to the situations described. The conditions to which participants are exposed are manipulated through changes in the situational descriptions. The impact of these conditions on participants' judgments is then assessed in the data-analysis stage.

Factorial surveys offer several benefits relative to traditional survey research. As participants are presented with randomly assigned vignettes, thereby leading to approximate factor orthogonality, factorial surveys offer a more controlled way to study the effects of multiple conditions in combination on professional judgments. Factorial surveys are also argued to be less susceptible to social desirability bias than traditional survey research (Alexander and Becker 1978; Hughes 1998; Wallander 2009). This is because the use of realistic vignettes encourages immersion, which tends to lower participants' awareness that they are under study. In business ethics research, factorial surveys are therefore often

\footnotetext{
1 There are three sub-ethnic levels of horde or umbrella clans (zhuz) in Kazakhstan: the younger umbrella clan (kishi zhuz), the middle umbrella clan (orta zhuz), and the elder umbrella clan (uly zhuz).
} 
Table 1 The vignettes: variables of interest and standardized text cues

\begin{tabular}{|c|c|}
\hline Variables of interest & Standardized text cue \\
\hline troduction and firm type & $\begin{array}{l}\text { 1. Imagine that you work as a manager at KAZNOM. KAZNOM is a state-owned company in Kazakhstan that } \\
\text { employs several hundred people. KAZNOM is majority owned by the state } \\
\text { You have been working at KAZNOM for a number of years. One of your responsibilities is to screen applications } \\
\text { and to select applicants for announced job positions. You have the decision-making authority to recommend and } \\
\text { hire applicants } \\
\text { 2. Imagine that you work as a manager at ALMA. ALMA is a private Kazakh company that employs several hundred } \\
\text { people. ALMA was founded by Kazakhstani private investors in } 2002 \\
\text { You have been working at ALMA for a number of years. One of your responsibilities is to screen applications and } \\
\text { to select applicants for announced job positions. You have the decision-making authority to recommend and hire } \\
\text { applicants } \\
\text { 3. Imagine that you work as a manager at EDEN. EDEN is a foreign-owned company in Kazakhstan that employs } \\
\text { several hundred people. EDEN is fully owned by an international corporation } \\
\text { You have been working at EDEN for a number of years. One of your responsibilities is to screen applications and } \\
\text { to select applicants for announced job positions. You have the decision-making authority to recommend and hire } \\
\text { applicants }\end{array}$ \\
\hline Power of referent & $\begin{array}{l}\text { 1. Today you are evaluating a male applicant who applied for a lower-management position in the production depart- } \\
\text { ment. The applicant sent in his application after noticing the job announcement in a local newspaper } \\
\text { 2. Today you are evaluating a male applicant who applied for a lower-management position in the production depart- } \\
\text { ment. A tax inspector suggested this candidate to you during a phone call last month }\end{array}$ \\
\hline Communal ties & $\begin{array}{l}\text { 1. You read the application package and notice that the applicant you are evaluating is one of your cousins } \\
\text { 2. You read the application package and notice that the applicant you are evaluating is a distant relative } \\
\text { 3. You read the application package and notice that the applicant you are evaluating is a good friend of yours } \\
\text { 4. You read the application package and notice that the applicant you are evaluating is a friend of one of your friends } \\
\text { 5. You read the application package. You do not personally know the applicant you are evaluating }\end{array}$ \\
\hline Qualification of candidate & $\begin{array}{l}\text { 1. You also note that the applicant is qualified for the position for which he has applied. He is motivated, and has the } \\
\text { required educational background and work experience } \\
\text { 2. You also note that the applicant is not qualified for the position for which he has applied. Although the applicant is } \\
\text { motivated, he does not have the required educational background and work experience }\end{array}$ \\
\hline
\end{tabular}

The standardized text cues produced a total of 60 unique situational descriptions. The final vignettes were presented in Russian

used to study sensitive topics (Fritzsche and Becker 1984; Robertson et al. 2002, 2010; Weber 1992).

One issue requiring attention is the risk that participants tire or become sensitive to the conditions being manipulated. It is therefore recommended that the number of vignettes per participant is neither too high nor too low, and that vignettes are kept reasonably concise (Weber 1992). Another issue relates to the plausibility of the vignettes, as some combinations of text cues may be perceived as more realistic than others. Pilot studies are therefore advisable. Finally, factorial surveys differ from true experiments in that the confounding of effects is not deliberately controlled but follows from the random assignment of vignettes to participants, leading to approximate rather than true factor orthogonality. This results in weaker coefficients than in true experimental designs, which implies that obtained results are often relatively conservative estimates (Atzmüller and Steiner 2010).

\section{The Study}

For this study, we asked 52 managers with recruitment experience in Kazakhstan to assume the role of a recruiting manager and to evaluate four random vignettes describing a typical application process in Kazakhstan. Each vignette was followed by questions designed to capture how the participants would handle the situation described in the vignette. Following a reduced random-selection factorial survey design (Wallander 2009), we constructed our set of vignettes by combining text cues related to four conditions. The central condition described the variable of interest, namely, the communal tie between the recruiting manager and the job candidate. The operationalization of this variable is described in "Measures." The three other sets of conditions described the context in which the recruitment process was situated. These included the type of firm in which the recruitment process was taking place, whether the job applicant in the vignette had been referred by a powerful external referent, and whether the applicant described in the vignette was qualified for the position. We describe these conditions in detail when we discuss our control variables.

The combinations of these four sets of conditions produced a total of 60 vignettes, each of which contained a unique, fictive, situational description of an application process. The vignettes were first written in English and then translated into Russian, after which they were backtranslated in order to ensure accuracy. Table 1 provides 
Scenario \#3132

Imagine that you work as a manager at EDEN. EDEN is a foreign-owned company in Kazakhstan that employs several hundred employees. EDEN is fully owned by an international corporation.

You have been working at EDEN for a number of years. One of your responsibilities is to screen applications and to select applicants for announced job positions. You have the decision-making authority to recommend and hire job applicants.

Today you are evaluating a male applicant who has applied for a lower management position in the production department. The applicant sent in his application after noticing the job announcement in a local newspaper.

You read the application package and notice that the applicant you are evaluating is a good friend of yours. You also note that the applicant is not qualified for the position for which he applied. Although the applicant is motivated, he does not have the required educational background and work experience.

Given the situation that you just read, how likely is it that you would:

1. Invite the applicant for a formal screening

to test his knowledge and skills?

2. Invite the applicant for an interview with you?

3. Invite the applicant for an interview with other managers or decision makers?

4. Recommend hiring the applicant?
Highly unlikely $1-2-3-4-5-6-7$ Highly likely

Highly unlikely $1-2-3-4-5-6-7$ Highly likely

Highly unlikely $1-2-3-4-5-6-7$ Highly likely

Highly unlikely $1-2-3-4-5-6-7$ Highly likely

Fig. 1 Example of a vignette from the factorial survey

an overview of the variables of interest and the standardized text cues that were combined to create the different vignettes.

Each vignette was followed by three questions designed to capture how participants would handle the situation described in the vignette. Participants were asked to indicate the likelihood that they would: (1) invite the candidate to take part in a formal screening process in order to assess the candidate's knowledge and skills, (2) invite the job candidate to a personal interview, and (3) invite the candidate to an interview with other managers. These decisions form a typical part of recruitment and selection processes in Kazakhstan (Minbaeva and Muratbekova-Touron 2013). We also included a fourth question asking respondents to indicate the likelihood that they would recommend the candidate for hiring. All answers were rated on a seven-point Likert scale. An example of a vignette used in the factorial survey is given in Fig. 1.
We included the firm-type condition to control for potential mediation processes. Communal ties (our manipulated variable) may cause variations in recruitment strategies (our dependent variable) through the identification of the participant with the type of firm described in the vignette. For instance, a participant working for a state-owned firm is likely to perceive behaviors that reflect the norms and values of that firm as appropriate. By manipulating the type of ownership in the vignette, we aimed to control for the possibility that our results are driven by respondents' identification with a specific type of firm.

To rule out other unobserved processes, we pre-tested the vignettes on four Kazakhstani managers responsible for recruitment and selection decisions. We evaluated their understanding of the vignettes, the suitability of the described situations, and the rationales for their responses to the described situations. We consequently made minor changes to the standardized text cues. 
Table 2 Operationalization of immediacy and relatedness in the context of Kazakhstan

\begin{tabular}{|c|c|c|}
\hline Structural attributes & Empirical definitions & Illustrative quotes \\
\hline \multirow[t]{2}{*}{ Immediacy } & Immediate clan ties & $\begin{array}{l}\text { It's just because of our culture. You respect your family, you support your friends (Manager, } \\
\text { private company, ethnic Russian) }\end{array}$ \\
\hline & Distant clan ties & $\begin{array}{l}\text { You know how they detect people's zhuz [umbrella clan attachment]? As you know, it is not } \\
\text { written anywhere. They just ask where the candidate finished his or her schooling during } \\
\text { the recruitment process. The answer may give a hint about their zhuz. This is important for } \\
\text { some Kazakhs (Professor, academic institution, Kazakh) }\end{array}$ \\
\hline \multirow[t]{2}{*}{ Relatedness } & Consanguineal clan ties & $\begin{array}{l}\text { Your sisters and brothers are the most important people in the world. They are your father's } \\
\text { blood. Friends come and go, but family will always support you (Professor, academic } \\
\text { institution, Kazakh) } \\
\text { All Kazaks are 'relatives.' If I were to hire every person with my family name, what would } \\
\text { happen to my organization? [Interviewer: "What if that person is a son of your father's } \\
\text { brother?"'] Then, of course, I would take him. He is my blood! (Director, public organiza- } \\
\text { tion, Kazakh) }\end{array}$ \\
\hline & Friendship-based clan ties & $\begin{array}{l}\text { Your blizki drug [real friend; close friend] will never betray you. You know him and you will } \\
\text { not be surprised. The element of trust is very important when you work with people (Chief } \\
\text { financial officer, private company, Kazakh) }\end{array}$ \\
\hline
\end{tabular}

\section{Sample}

Our sample consists of 206 observations provided by 52 managers responsible for recruitment and selection decisions in firms located in Kazakhstan. The factorial survey was administered face-to-face in 2012 in the cities of Almaty, Astana, and Karaganda. We informed each participant that the objective of the study was to improve our understanding of recruitment and selection practices in Kazakhstan, and we guaranteed full anonymity. Given the sensitivity of the topic, we selected an initial group of managers and subsequently adopted a snowball method (Biernacki and Waldorf 1981) to locate additional participants. Each participant received a randomly selected subset of four vignettes. However, one participant rated only two vignettes due to time limitations. Thus, we collected information on 234 vignettes.

In addition to the factorial survey, participants were asked to fill out a questionnaire to collect data on personal characteristics, such as age and ethnicity. The questionnaire also contained questions related to the participant's work experience (e.g., foreign work experience; types of organizations). As seven respondents only answered some of these questions, the number of observations was reduced to 206 .

We complemented the factorial survey with semi-structured follow-up interviews with 48 participants. The interviews lasted between $20 \mathrm{~min}$ and two hours. They were conducted in Russian, although some anecdotes and wordings in Kazakh were used in certain interviews. Often, the respondents initiated the follow-up conversation themselves, as they had reflected on their choices or wanted to comment on their decisions. When this was not the case, we asked more general questions, such as "Why did you respond in this way?" and "What was the most decisive factor in your decision?" We also posed questions specific to the participants' choices.
We revisited Kazakhstan in 2014 to conduct follow-up interviews on the basis of questions that emerged as a result of our analysis.

\section{Measures}

In line with our hypotheses, the focal condition in the vignettes was the communal tie between the participant and the job candidate. In the following, we describe how the two focal attributes of communal ties-relatedness and immediacy - were operationalized in the vignettes through the use of text cues. We then describe how we measured the hypothesized coping strategies.

\section{Communal Ties with the Job Candidate}

For testing purposes, we operationalized ties with related job applicants as consanguineal ties and ties with unrelated job candidates as friendship ties. We distinguished between directly connected and indirectly connected community members to operationalize immediate and distant clan ties, respectively. Table 2 contains quotes from the follow-up interviews that illustrate these distinctions.

In order to test our hypotheses, we combined the dimensions of relatedness and immediacy, and defined four dummy variables to describe the tie between the participant and the job applicant described in the vignettes. As shown in Table 3, the different types of clan ties were operationalized as cousin (the candidate is related and directly connected to the participant), distant relative (the candidate is related but indirectly connected to the participant), close friend (the candidate is unrelated but directly connected to the participant), and friend of a friend (the candidate is unrelated and indirectly connected to the participant). In 
Table 3 Operationalization of immediacy and relatedness in the vignettes

\begin{tabular}{|c|c|c|}
\hline \multirow[t]{2}{*}{ Immediacy } & \multicolumn{2}{|l|}{ Relatedness } \\
\hline & $\begin{array}{l}\text { Consanguin- } \\
\text { eal clan ties } \\
\text { (related) }\end{array}$ & $\begin{array}{l}\text { Friendship-based } \\
\text { clan ties (unre- } \\
\text { lated) }\end{array}$ \\
\hline $\begin{array}{l}\text { Immediate clan ties (direct } \\
\text { ties) }\end{array}$ & Cousin & Close friend \\
\hline Distant clan ties (indirect ties) & Distant relative & Friend of a friend \\
\hline
\end{tabular}

addition, we defined a separate text cue, unacquainted, to create scenarios in which a job applicant has no community ties with the participant.

\section{Coping Strategies}

Based on the first three recruitment and selection decisions (see Fig. 1), we operationalized the response strategies to fit the context of Kazakhstan. Specifically, we expected participants adopting an acquiescence strategy to attempt to comply with clan obligations and communal norms for opportunity sharing by shielding the job applicant from all of the evaluative steps in the recruitment and selection process. In other words, we expected acquiescence to be reflected in low scores for the likelihood of inviting the applicant to participate in formal screening, a personal interview, or an interview with other managers. We expected participants following a compromise strategy to also show little inclination to expose the candidate to external judgment in the form of formal testing or an interview with other managers. In contrast to participants following an acquiescence strategy, we expected participants seeking a compromise between their community and work obligations to be more likely to invite the applicant to a personal interview. This is because personal interviews can serve as minimal fulfillment of community obligations, and because personal interviews provide a chance to shape or alter an applicant's expectations of the outcome of the recruitment process. For example, a manager can use interviews to clarify the qualifications necessary for a particular position. Therefore, personal interviews may serve as a means to achieve partial conformity to the institutional demands of both the community and the workplace.

In contrast, we expected participants who chose to avoid their clan obligations to do so by precluding the necessity of conforming with community obligations (Oliver 1991; Pache and Santos 2010). In other words, we expected participants choosing an avoidance strategy to subject the job applicant to formal screening and to the judgment of other decision makers, rather than to interview the candidate directly. Such responses are likely when community obligations cannot be ignored but recruiting managers are either unable or unwilling to comply with clan obligations. Finally, we expected participants adopting a defiance strategy to explicitly challenge or reject their obligations to community members. We therefore expected these individuals to subject the job applicant to all three steps in the recruitment and selection process. Table 4 shows the expected distribution of the recruitment and selection decisions for the four strategic-response categories, and lists several quotes from the follow-up interviews that illustrate these four strategies.

We validated the operationalization of the response strategies by applying statistical cluster techniques. Cluster analyses are widely used to determine natural groupings of observations (Everitt et al. 2011; Gordon 1999). However, as these analyses are generally intended for generating, rather than testing, hypotheses, they lack $p$ values (Everitt 1993). We applied a partition-clustering method that breaks the observations into a distinct number of non-overlapping $k$ groups. More specifically, we used a mean-based iterative partitioning procedure to assign each observation to the group with the closest mean. On the basis of that categorization, new group means were determined. These steps were reiterated until no observations changed groups from the previous iteration. We used Euclidean distance to determine the similarity between observations. The results of the cluster analysis closely correspond with our operationalization of the response strategies (Table 5). The responses contained in group 1 (acquiescence) scored low (below average) on each of the three items. The opposite is observed for responses in group 4 (defiance), which scored high (above average) on each of the three items. In the middle, we find behaviors that mirror the compromise (group 2) and avoidance (group 3) strategies. In the former case, study participants were inclined to invite the applicant to a personal interview, while participants in the latter case preferred to invite the applicant to a formal screening and to an interview with other managers. Based on this analysis, we defined four dummy variables to be used as dependent variables in our econometric model: acquiescence, compromise, avoidance, and defiance. The correlations between these variables are included in the table with descriptive statistics and correlations (Table 6).

\section{Control Variables}

We controlled for various factors that may influence the participants' response strategies. First, we accounted for the possibility that responses to institutional demands may be affected by the degree of hybridity in the organizational context (Pache and Santos 2013). As described above, the influence of clanism on recruitment and selection practices in Kazakhstan may be contingent on the company's ownership type. Previous research (Minbaeva et al. 2007; Minbaeva and Muratbekova-Touron 2013) indicates that the pressure 
Table 4 Empirical operationalization of the response strategies

\begin{tabular}{|c|c|c|c|c|}
\hline \multirow[t]{2}{*}{ Response strategies } & \multicolumn{3}{|c|}{ Likelihood of inviting an applicant for: } & \multirow[t]{2}{*}{ Illustrative quotes } \\
\hline & Formal screening & $\begin{array}{l}\text { A personal } \\
\text { interview }\end{array}$ & $\begin{array}{l}\text { An interview } \\
\text { with other man- } \\
\text { agers }\end{array}$ & \\
\hline Acquiescence & Low & Low & Low & $\begin{array}{l}\text { To invite this candidate for an interview with other managers, I would } \\
\text { also not be able to do that. Why? Because I don't want to show that } \\
\text { some of my relatives may be stupid! ... For a low-level position ... I } \\
\text { would [still] recommend, not a problem; even my relatives. Yes, yes } \\
\text { guys, I have a Western education, but still, I mean, in Kazakhstan } \\
\text { you have to do that! (Academic, academic institution, Kazakh) }\end{array}$ \\
\hline Compromise & Medium/low & High & Medium/low & $\begin{array}{l}\text { I don't know ... if he is my relative ... of course I don't want all my } \\
\text { other relatives telling me that I'm so arrogant that I will not even } \\
\text { invite him to talk! (Manager, private company, ethnic Russian) }\end{array}$ \\
\hline Avoidance & High & Low & High & $\begin{array}{l}\text { These [recruitment and selection] rules are also in place to protect our } \\
\text { employees. Their relatives may be offended. They may say 'You are } \\
\text { the bastyk ['boss'] and you cannot take me or my nephew?' In this } \\
\text { case, our managers can say 'Look, we have company rules. I am } \\
\text { unable to do it differently. It does not depend on me' (HR manager, } \\
\text { subsidiary of a Czech MNE, Korean ethnicity) } \\
\text { For me, the most important thing is competence. I have a cloud of } \\
\text { relatives who are constantly asking me to help them find a job. I use } \\
\text { the company processes to politely otshivat ['refuse' in Russian slang] } \\
\text { them but to avoid offending them (Director of executive education } \\
\text { department, academic institution, Kazakh) }\end{array}$ \\
\hline Defiance & High & High & High & $\begin{array}{l}\text { One of the missions of our HR department is to stop all of these rela- } \\
\text { tionships-the hiring of relatives, the use of friends, etc. At least one } \\
\text { additional HR manager has to assist in all recruitment interviews in } \\
\text { order to avoid all of these issues (HR Manager, academic institution, } \\
\text { Kazakh) }\end{array}$ \\
\hline
\end{tabular}

Table 5 Validation of the response strategies

\begin{tabular}{|c|c|c|c|c|c|c|}
\hline & Mean & SD & Acquiescence & Compromise & Avoidance & Defiance \\
\hline Likelihood of inviting an applicant for formal screening & 4.77 & 2.42 & 1.93 & 4.39 & 5.07 & 6.75 \\
\hline Likelihood of inviting an applicant for an interview with the decision maker & 4.39 & 2.49 & 1.44 & 5.63 & 1.62 & 6.49 \\
\hline $\begin{array}{l}\text { Likelihood of inviting an applicant for an interview with other decision- } \\
\text { making managers }\end{array}$ & 4.68 & 2.47 & 1.24 & 4.25 & 5.76 & 6.76 \\
\hline Number of observations & & & 59 & 51 & 29 & 92 \\
\hline
\end{tabular}

to conform to clan obligations is strong in state-owned companies, moderate in private companies, and weak in MNC subsidiaries. To account for this, we varied the type of firm in the vignettes as described above (see Table 1). We defined the following dummy variables to qualify the type of firm: privately owned firm, foreign-owned firm, and state-owned firm. The latter was used as the baseline in the estimation.

In addition, responses to institutional pressures may be affected by resource dependencies (Oliver 1991; Pfeffer and Salancik 1978). To account for this possibility, we included a text cue in the vignettes signaling whether the candidate had been referred by a powerful external referent (i.e., an inspector from the tax authority; see Table 1). In our analyses, the dummy variable tax inspector took the value of 1 if the candidate had been recommended by a tax inspector during a phone call in the previous month. The baseline (tax inspector equal to 0 ) was the situation in which the candidate submitted an application after noticing a job advertisement in a local newspaper. As meritocracy might be downplayed in contexts in which community norms are more pervasive, we also included a text cue in the vignettes that signaled whether the candidate was qualified. We subsequently added the dummy variable unqualified to the model, which equaled 1 if the candidate described in the vignette was not qualified for the position. The baseline consisted of situations in which the candidate was qualified.

Several participant characteristics were added to the model based on data collected through the questionnaire. 
Table 6 Descriptive statistics

\begin{tabular}{|c|c|c|c|c|c|c|c|c|c|c|c|}
\hline & 1 & 2 & 3 & 4 & 5 & 6 & 7 & 8 & 9 & 10 & 11 \\
\hline Mean & 0.26 & 0.23 & 0.12 & 0.39 & 0.19 & 0.22 & 0.16 & 0.23 & 0.20 & 0.52 & 0.27 \\
\hline SD & 0.44 & 0.42 & 0.32 & 0.49 & 0.40 & 0.41 & 0.37 & 0.42 & 0.40 & 0.50 & 0.45 \\
\hline \multicolumn{12}{|l|}{ (1) Acquiescence } \\
\hline (2) Compromise & -0.32 & & & & & & & & & & \\
\hline (3) Avoidance & -0.22 & -0.20 & & & & & & & & & \\
\hline (4) Defiance & -0.48 & -0.44 & -0.29 & & & & & & & & \\
\hline (5) Cousin & 0.07 & -0.09 & 0.01 & 0.01 & & & & & & & \\
\hline (6) Distant relative & 0.17 & 0.02 & -0.12 & -0.09 & -0.26 & & & & & & \\
\hline (7) Close friend & -0.05 & 0.01 & 0.17 & -0.08 & -0.21 & -0.23 & & & & & \\
\hline (8) Friend of a friend & -0.11 & -0.05 & 0.02 & 0.13 & -0.27 & -0.29 & -0.24 & & & & \\
\hline (9) Unacquainted & -0.08 & 0.11 & -0.07 & 0.02 & -0.24 & -0.26 & -0.22 & -0.27 & & & \\
\hline (10) Unqualified & 0.39 & 0.10 & -0.11 & -0.37 & 0.00 & 0.13 & -0.03 & -0.06 & -0.04 & & \\
\hline (11) Privately owned firm & -0.12 & 0.01 & 0.12 & 0.02 & -0.05 & 0.02 & -0.09 & 0.03 & 0.08 & -0.07 & \\
\hline (12) Foreign-owned firm & 0.06 & 0.09 & -0.11 & -0.06 & -0.11 & 0.08 & -0.03 & -0.03 & 0.09 & 0.02 & -0.41 \\
\hline (13) Tax inspector & -0.07 & 0.15 & 0.00 & -0.06 & 0.04 & 0.01 & 0.06 & -0.11 & 0.01 & 0.09 & -0.09 \\
\hline (14) Kazakh ethnicity & 0.08 & -0.07 & -0.01 & -0.01 & 0.00 & 0.12 & -0.06 & 0.06 & -0.12 & 0.00 & 0.01 \\
\hline (15) Female & -0.16 & 0.14 & -0.05 & 0.06 & -0.05 & 0.05 & 0.02 & 0.02 & -0.04 & -0.01 & -0.07 \\
\hline (16) Age & -0.13 & 0.07 & 0.17 & -0.06 & -0.02 & -0.07 & 0.07 & 0.02 & 0.01 & -0.06 & 0.06 \\
\hline (17) Company experience & -0.09 & -0.02 & 0.09 & 0.04 & -0.01 & -0.03 & 0.03 & -0.02 & 0.03 & 0.03 & 0.09 \\
\hline (18) Senior manager & 0.01 & 0.14 & 0.13 & -0.22 & -0.07 & -0.03 & 0.05 & 0.02 & 0.03 & 0.01 & -0.05 \\
\hline (19) Foreign work experience & 0.07 & -0.13 & -0.09 & 0.12 & 0.04 & 0.00 & -0.05 & -0.07 & 0.07 & 0.06 & 0.04 \\
\hline (20) Western MNE & 0.08 & 0.09 & -0.11 & -0.07 & -0.08 & 0.03 & -0.11 & -0.01 & 0.16 & 0.01 & -0.05 \\
\hline (21) Privately owned background & -0.22 & -0.09 & 0.12 & 0.19 & 0.16 & -0.04 & -0.09 & -0.04 & 0.00 & -0.02 & 0.03 \\
\hline \multirow[t]{2}{*}{ (22) Foreign-subsidiary background } & 0.22 & 0.00 & -0.13 & -0.11 & -0.07 & 0.04 & -0.02 & 0.06 & -0.02 & 0.04 & -0.05 \\
\hline & 12 & 13 & 14 & 15 & 16 & 17 & 18 & 19 & 20 & 21 & 22 \\
\hline Mean & 0.31 & 0.50 & 0.67 & 0.65 & 40.32 & 7.15 & 0.36 & 0.04 & 0.16 & 0.46 & 0.23 \\
\hline SD & 0.46 & 0.50 & 0.47 & 0.48 & 10.87 & 8.46 & 0.48 & 0.11 & 0.36 & 0.50 & 0.42 \\
\hline
\end{tabular}

(1) Acquiescence

(2) Compromise

(3) Avoidance

(4) Defiance

(5) Cousin

(6) Distant relative

(7) Close friend

(8) Friend of a friend

(9) Unacquainted

(10) Unqualified

(11) Privately owned firm

(12) Foreign-owned firm

(13) Tax inspector

(14) Kazakh ethnicity

(15) Female

(16) Age

(17) Company experience

(18) Senior manager

(19) Foreign work experience

(20) Western MNE

(21) Privately owned background

$$
0.11
$$

$\begin{array}{rrrrrrrrrr}0.06 & 0.00 & & & & & & & \\ 0.07 & 0.10 & 0.09 & & & & & & \\ -0.02 & 0.11 & 0.09 & 0.05 & & & & & \\ -0.07 & 0.02 & 0.20 & 0.01 & 0.70 & & & & \\ -0.02 & -0.06 & -0.23 & -0.45 & -0.01 & 0.00 & & & \\ -0.01 & -0.11 & -0.04 & -0.23 & -0.02 & -0.04 & -0.04 & & \\ 0.09 & 0.10 & 0.07 & 0.07 & -0.08 & -0.20 & -0.10 & 0.06 & \\ 0.02 & 0.04 & -0.09 & -0.13 & -0.15 & -0.13 & 0.09 & 0.03 & -0.18\end{array}$


Table 6 (continued)

\begin{tabular}{|c|c|c|c|c|c|c|c|c|c|c|c|}
\hline & 12 & 13 & 14 & 15 & 16 & 17 & 18 & 19 & 20 & 21 & 22 \\
\hline Mean & 0.31 & 0.50 & 0.67 & 0.65 & 40.32 & 7.15 & 0.36 & 0.04 & 0.16 & 0.46 & 0.23 \\
\hline SD & 0.46 & 0.50 & 0.47 & 0.48 & 10.87 & 8.46 & 0.48 & 0.11 & 0.36 & 0.50 & 0.42 \\
\hline (22) Foreign-subsidiary background & -0.04 & -0.03 & -0.21 & 0.10 & -0.15 & -0.26 & -0.13 & 0.01 & 0.27 & -0.51 & \\
\hline
\end{tabular}

$N=206$. Correlations greater than 0.10 are significant at least at $p<0.10$

Table 7 Analysis of the effects of communal ties on individuals' response strategies

\begin{tabular}{|c|c|c|c|c|}
\hline \multirow[t]{3}{*}{ Variable } & \multicolumn{4}{|l|}{ Response strategy } \\
\hline & Model 1 & Model 2 & Model 3 & Model 4 \\
\hline & Acquiescence & Compromise & Avoidance & Defiance \\
\hline Cousin & $0.86(0.36)^{* *}$ & $-0.01(0.40)$ & $0.00(0.29)$ & $-0.68(0.32)^{* *}$ \\
\hline Distant relative & $0.83(0.32)^{* * *}$ & $0.17(0.36)$ & $-0.40(0.45)$ & $-0.54(0.34)$ \\
\hline Close friend & $0.42(0.39)$ & $0.19(0.38)$ & $0.60(0.36)^{*}$ & $-0.75(0.33)^{* *}$ \\
\hline Unacquainted & $0.36(0.36)$ & $0.42(0.34)$ & $-0.04(0.42)$ & $-0.34(0.32)$ \\
\hline Unqualified & $1.42(0.28)^{* * *}$ & $0.30(0.24)$ & $-0.18(0.22)$ & $-1.17(0.26)^{* * *}$ \\
\hline Privately owned firm & $-0.38(0.25)$ & $0.34(0.31)$ & $0.32(0.30)$ & $-0.36(0.24)$ \\
\hline Foreign-owned firm & $0.25(0.27)$ & $0.34(0.25)$ & $-0.32(0.37)$ & $-0.36(0.20)^{*}$ \\
\hline Tax inspector & $-0.33(0.23)$ & $0.35(0.21)^{*}$ & $-0.02(0.24)$ & $0.01(0.17)$ \\
\hline Kazakh ethnicity & $0.38(0.31)$ & $-0.15(0.33)$ & $0.35(0.31)$ & $-0.30(0.31)$ \\
\hline Female & $-0.86(0.36)^{* *}$ & $0.75(0.34)^{* *}$ & $0.08(0.30)$ & $-0.03(0.37)$ \\
\hline Age & $-0.01(0.01)$ & $0.01(0.01)$ & $0.03(0.02)^{*}$ & $-0.01(0.01)$ \\
\hline Senior manager & $-0.16(0.37)$ & $0.82(0.30)^{* * *}$ & $0.56(0.26)^{* *}$ & $-0.97(0.35)^{* * *}$ \\
\hline Foreign work experience & $-0.31(1.07)$ & $-1.74(1.33)$ & $-2.63(1.28)^{* *}$ & $1.88(1.37)$ \\
\hline Western MNE & $0.10(0.36)$ & $0.33(0.39)$ & $-0.53(0.45)$ & $-0.39(0.44)$ \\
\hline Privately owned background & $-0.77(0.34)^{* *}$ & $-0.30(0.34)$ & $0.61(0.40)$ & $0.43(0.33)$ \\
\hline Foreign-subsidiary background & $0.45(0.37)$ & $-0.24(0.40)$ & $0.10(0.51)$ & $-0.46(0.35)$ \\
\hline Constant & $-0.84(0.88)$ & $-2.27(0.78) * * *$ & $-3.16(0.97)^{* * *}$ & $1.85(0.74)^{* *}$ \\
\hline Wald $\chi^{2}$ & $53.33 * * *$ & $31.82 *$ & $52.86^{* * *}$ & $63.29 * * *$ \\
\hline Log-pseudolikelihood & -80.41 & -94.58 & -59.81 & -104.63 \\
\hline McFadden's adjusted pseudo- $R^{2}$ & 0.32 & 0.15 & 0.19 & 0.24 \\
\hline
\end{tabular}

Probit regressions. Friend of a friend, combining indirect and unrelated ties, is used as the baseline for communal ties

Robust standard errors corrected for heteroscedasticity and cluster-correlated data are in brackets $N=206 . * p<0.10 ; * * p<0.05 ; * * * p<0.01$ (two-tailed tests applied)
More specifically, we controlled for the participant's ethnicity in order to isolate possible ethnicity-related effects on the response strategies. The variable Kazakh ethnicity took the value of 1 if the participant was a Kazakh, and 0 otherwise. We also controlled for the gender (female) and age (age) of the participant, and for whether the participant worked for a western MNE (western MNE). We also controlled for the participant's foreign work experience (foreign work experience), which we measured as the ratio of years worked abroad to total years worked. The dummy variable senior manager equaled 1 if the participant was either a senior manager or the owner of a firm. Finally, we sought to control for the participants' degree of familiarity with the organizational logic of the workplaces described in the vignettes (see also Pache and Santos 2013). The variables privately owned background and foreign-subsidiary background allowed us to control for the contexts that participants had experienced in their previous jobs. Participants who had worked for stateowned companies or who did not have previous work experience served as the baseline.

\section{Findings}

Table 6 presents the descriptive statistics and correlations for all variables considered in the econometric model. We estimated the effect of immediacy and relatedness on the likelihood that a manager would adopt each response strategy 
(i.e., acquiescence, compromise, avoidance, and defiance). Given the dichotomous nature of these dependent variables, we run four separate probit regression estimations. In Table 7, Model 1 tests Hypothesis 1 in which acquiescence is the dependent variable. Compromise is the dependent variable in Model 2, which empirically tests Hypothesis 2. In Model 3, which tests Hypothesis 3, we consider avoidance as the dependent variable. Finally, we test Hypothesis 4 in Model 4, which has defiance as the dependent variable. In each model, we use the variable friend of a friend (i.e., the job candidate is unrelated and indirectly connected to the decision maker) as the baseline. Thus, the estimated effects of the variables cousin, distant relative, and close friend are relative to the effect of friend of friend. Although the vignettes were randomly assigned to each participant, nonindependence among the observations may arise because each respondent was usually responsible for four observations in the dataset (Greene 2000). Therefore, we used the Stata cluster option to rule out respondent-level effects and to obtain a robust variance estimate that adjusted for withinrespondent correlations (Williams 2000).

Model 1 (Table 7) reports the effects of our independent variables on the likelihood of a recruitment manager employing an acquiescence strategy. Based on Hypothesis 1, we would expect only the variable cousin to be positive and significant. However, the coefficients of the variables cousin and distant relative are both positive and statistically significant at $p<0.05$ and $p<0.01$, respectively. This indicates that managers related to a job applicant are more likely to rely on acquiescence to manage communal norms and obligations. This effect is independent of the immediacy of the tie. The results also imply that direct ties favor acquiescence only under conditions of relatedness. As shown by the coefficient of the variable close friend, the likelihood that a manager will choose acquiescence does not increase with unrelated job candidates to whom the manager is directly connected. Overall, our findings provide support for Hypothesis 1, but they also show a more general positive effect of relatedness on acquiescence. In Model 2, none of the social tie variables are statistically different from the baseline variable friend of a friend. Accordingly, we do not find support for Hypothesis 2. In Model 3, the coefficient of the variable close friend is positive and statistically significant at $p<0.1$, while the coefficients of cousin and distant relative are not significant. These results provide support for Hypothesis 3 and suggest that when job applicants are unrelated but directly connected, managers are more likely to use avoidance as a response strategy in their handling of the recruitment process. Finally, in Model 4, the negative and statistically significant $(p<0.05)$ coefficients of the variables cousin and close friend suggest that defiance is more likely when the job applicant is indirectly connected to the manager. However, as the coefficient of distant cousin is negative but only borderline significant $(p<0.109)$, the evidence that the job candidate should also be unrelated to trigger defiance is not particularly strong. These results provide partial support for Hypothesis 4. In other words, indirect ties between the manager and the job applicant might be sufficient to trigger a meritocratic recruitment and selection process.

The results of the estimations largely confirm the suggestion that relatedness and immediacy are two distinct yet interrelated attributes of social ties that together explain how the managers in our sample handle communal norms and obligations related to favoritism during recruitment processes. The main exception is the lack of a clear pattern in the relation between social ties and compromise as response strategy (H2). While this finding is unexpected, our qualitative findings help with its interpretation. More specifically, our interviews suggested the presence of differences between ethnic groups in terms of the perceived boundaries between immediate and distant consanguineal ties. Participants with different ethnic backgrounds appeared to differ in their perceptions of which relatives were close and which were more peripheral. As one participant explained:

Ethnic Koreans [a sizeable historic minority in Kazakhstan] are less clan-oriented than Kazakhs. Our family is like a European family, as we consider the "family" to be a small entity including a mother, a father, brothers, and sisters (HR manager for a western MNE, ethnic Korean)

In contrast, participants who were ethnic Kazakhs demonstrated much greater awareness of familial affiliations and extended kinship ties. This reflects the cultural expectation of zheti ata, the ability to list one's genealogical background for the past seven generations. In addition, the sense of immediacy and obligation expressed by ethnic Kazakhs tended to extend beyond relatives who were directly related to include more distant relatives. As one ethnic Kazakh explained:

We are not Russians who see only their very close relatives [parents or siblings]. For us Kazakhs, relatives are important. For example, if my husband's cousin invited us to his son's wedding, we would see all of our relatives there-not only the relatives of the cousin and my husband but also my own relatives. If someone asks me to help a relative, I try to do so. (Professor, academic institution, Kazakh)

Similarly, when asked to elaborate on the distinction between relatives and friends, a participant clarified:

A friend is a friend, a relative is a relative! [laughter] You are responsible for your relatives, but you are not responsible for your friends! ... Any person who is a little bit better educated, has a slightly higher posi- 
tion, or has a slightly higher salary feels responsible for those who have less than them ... Nobody pushes you, nobody pressures you. It is just somewhere here. You feel that you are responsible. (HR professional, private company)

Thus, although all ethnic groups in Kazakhstan share an understanding of the distinction between related and unrelated community members, the perceived obligation to relatives appears to vary less between direct and indirect ties among ethnic Kazakhs than in other ethnic groups. These findings highlight that immediacy and relatedness may carry different structural connotations in different cultures and communities (see, e.g., Pitt-Rivers 1973), and they may explain the unexpected non-significant discriminating effect of immediacy in conjunction with related job candidates. Therefore, although the results generally support our expectations, they illustrate that measures to capture differences in immediacy may need to be separately defined for different communities.

The combination of methods provided us with several additional insights. For example, our post hoc interviews suggested that managers often decoupled their behaviors for coping with community members from their actual hiring decisions. In fact, several participants who chose to shield a job candidate from formal selection-process procedures (i.e., acquiescence) also stated that they were hesitant to recommend that candidate for hiring. These participants highlighted that although accommodating the norm-related expectations of clan members was important, actually recommending a clan member for hiring might hurt their own credibility and career prospects within the organization. As one participant explained:

I do not want to recommend my relative [for hiring] because I do not want his name to be associated with mine. I do not want others in the company to remember that this person is my relative. (Finance director, subsidiary of a foreign bank, Kazakh)

Given these intriguing findings, we returned to the quantitative analysis. We conducted additional estimations to explore the relation between the participants' response strategies and the likelihood that a candidate would be recommended for hiring. Interestingly, the results of this post hoc analysis show that recommending a candidate for hiring is less likely in the case of an acquiescence strategy $(\beta$ $=-1.13, p<0.001)$ than in the case of a compromise $(\beta$ $=-0.57, p<0.001)$, avoidance $(\beta=-0.53, p<0.05)$, or defiance strategy (baseline). ${ }^{2}$ In other words, the strategies

\footnotetext{
${ }^{2}$ Based on the statistical tests for equality of the regression coefficients, the difference between the coefficients of acquiescence and compromise is statistically significant $(F(1,51)=11.04 ; p<0.01)$. The same is true for the difference between the coefficients of acquiescence and avoidance $(F 1,51)=4.90 ; p<0.05)$.
}

managers use to navigate communal favoritism during recruitment processes are not necessarily aligned with their actual intentions to recommend a community member for hire. Instead, these results suggest that how managers handle communal favoritism during recruitment processes is relatively decoupled from their actual recruitment intentions and decisions.

We also examined our data for signs of potential social desirability bias. Given the stigma attached to favoritism, we expected social desirability to manifest itself as the desire to come across as fair, objective, and merit-based. We therefore applied two-sample $t$ tests to assess whether there was indeed a general tendency to apply best practice in recruitment and selection to all applicants, such as formal screenings and interviews, or whether participants were inclined to shield unqualified applicants from best practice. We found that participants were less likely to submit unqualified job applicants to formal screening (mean 3.92) than qualified ones (mean $=5.63)$, and that the difference is significant $(p<0.001)$. We obtained comparable results when analyzing the other selection practices. Although it is difficult to rule out social desirability, such patterns would be unlikely if our data were systematically affected by social desirability bias.

\section{Discussion and Conclusion}

Favoritism poses a significant challenge to organizations in collectivist societies (Pearce 2015). In this study, we sought to complement recent work on managerial attitudes towards favoritism (Chen et al. 2015; Wated and Sanchez 2015) with insights into how managers in collectivist societies handle favoritism-related communal norms and obligations in their daily work. To this end, we used insights from institutional theory to advance a communal perspective on favoritism, which identifies communal norms and obligations as a source of favoritism in recruitment and selection. Drawing on the notion of social cues (DiMaggio 1997), we argued that exposure to job applicants from one's community may evoke communal norms and obligations, including expectations of favoritism, even in workplaces where meritocratic HRM practices are common. We then hypothesized that managers' strategies for handling communal norms and obligations towards favoritism are contingent on their communal ties with job applicants. The results of our factorial survey and qualitative interviews shed new light on these relations, and advance research on favoritism and institutional theory.

Our paper contributes to our understanding of favoritism in several ways. First, to the best of our knowledge, this study is the first to examine the strategies managers use to cope with communal favoritism during selection and recruitment processes, and the determinants of those responses. Recruiting managers often face a difficult social conundrum, 
especially in collectivist societies. On the one hand, they may experience considerable pressure to share employment opportunities with family members and acquaintances. On the other hand, studies of attitudes towards and perceptions of favoritism (e.g., Chen et al. 2015; Wated and Sanchez 2015 ) indicate that engaging in favoritism often carries considerable social costs, which can hurt managers' careers. To capture these dynamics, we advanced a communal perspective on favoritism in recruitment and selection to complement existing perspectives. This perspective differs from extant perspectives in that it conceptualizes low-level favoritism as a social expectation to be managed, and identifies communal norms and obligations as an important source of favoritism in recruitment and selection. In addition, it identifies communal ties with job applicants as an antecedent to the ways in which managers handle these social expectations during recruitment processes.

The results of the factorial survey appear to support our theorizing. Specifically, we find that when a job applicant is related and the communal tie is direct, our participants are inclined to acquiescence to communal norms in their handling of recruitment processes. Furthermore, our participants pursue avoidance strategies when the applicant is unrelated but directly connected, while the handling of the recruitment process reflects defiance in cases where the applicant is unrelated and indirectly connected. These results appear to confirm our expectation that the strategies managers adopt to handle favoritism norms vary with the communal tie between the recruiting manager and the job applicant.

The findings are also in line with our theorization that the two focal attributes of communal ties-immediacy and relatedness-have different implications for the cueing function of social ties. More specifically, the variation in responses we observe supports our expectation that immediacy affects the degree of social obligation that managers experience, while relatedness affects the leeway they have in handling communal norms and obligations towards job applicants from their own communities. These findings are important because they illustrate the value of communityoriented perspectives for an improved understanding of the causes and consequences of favoritism, especially in collectivist societies. In particular, the findings suggest that paying more attention to the communities in which managers are embedded and their ties to members of those communities can provide valuable insights into when and how managers experience social pressure to engage in favoritism, and the effects of that pressure on their daily handling of recruitment processes.

Another contribution lies in our finding that the strategies managers use to cope with communal favoritism are relatively decoupled from their recruitment intentions. While managers' handling of the recruitment process varies with their communal ties to the job applicant, those same ties have relatively little effect on their professional judgments regarding whether to recommend the applicant for hire. In fact, hiring decisions are mainly driven by the applicants' qualifications. Just as organizations may engage in decoupling to buffer task activities from institutional demands (Bromley and Powell 2012; Meyer and Rowan 1977), our findings suggest that recruiting managers may decouple their recruitment decisions from their handling of the recruitment process. This allows them to adhere to communal norms and obligations, if only ceremoniously, while making decisions that are more aligned with organizational norms and their own career interests.

Our findings regarding the decoupling of recruiting managers' coping strategies from their recruitment decisions are significant because they paint a more nuanced picture of the role and influence of recruiting managers in societies where favoritism is widespread. Recruiting managers in these societies are often viewed as the human conduits of local norms of favoritism or even as favoritism's instigators. In contrast, our findings suggest that recruiting managers may play a crucial role in mitigating the effects of social expectations on organizational recruitment decisions. While recruiting managers may seemingly be the "perfect villains" in societies plagued by favoritism (see, e.g., Mozur and Sang-Hun 2017), categorizing them as such may do injustice to the daily work many of them may do to shield organizations from favoritism and its many side effects (Pearce 2015; Pearce et al. 2000).

A related implication is that favoritism in recruitment may be an even greater challenge than previously suspected. The significant degree of decoupling we observe suggests that merely examining actual cases of favoritism in recruitment and promotion decisions may hide much of the mitigating work that occurs below the surface. This also highlights the value of complementing studies of attitudes and perceptions towards favoritism (e.g., Chen et al. 2015; Wated and Sanchez 2015) with studies that look into how recruiting managers and organizations cope with this work-related challenge in practice (Jones and Stout 2015).

\section{Limitations and Future Research}

Although the findings generally confirm our expectations, our paper is not without limitations. A first limitation is that we did not measure the extent to which study participants experienced communal norms directly. The vignettes used in our factorial survey were designed to induce varying degrees of communal norms and obligations in the participants. However, the absence of manipulation checks means that we have no direct measure of the actual extent to which the participants in our study experienced these norms. There are, however, multiple indications that the manipulations were indeed successful. These include, first, the quantitative 
support for almost all of our hypotheses and the absence, to our knowledge, of plausible alternative theoretical explanations for our findings. Other indications are the initial observations from our pilot and the reported insights gained from the qualitative follow-up interviews. These factors make that we believe there is little reason to doubt that the uncovered relationship between communal ties and managers' coping strategies is mediated by a construct other than communal norms and obligations.

A second limitation is that we did not consider manipulation (Oliver 1991) as a strategy that recruiting managers may use to cope with communal norms of favoritism. We refrained from including this response strategy in our quasi-experimental design due to our interest in the cueing function of incidental exposure to community members during recruitment and selection processes, and managers' responses to such instances. In contrast, the manipulation of institutional demands is often associated with forms of engagement that are sustained over time, such as social movements (Lounsbury et al. 2003; Rao et al. 2003). Nevertheless, we recognize the potential for manipulation at the individual level, especially in situations characterized by a long-term conflict between communal and professional or organizational norms in recruitment and selection processes. Such conflicts are particularly conducive to critical reflections, which often precede attempts at institutional change (Seo and Creed 2002; Hardy and Maguire 2008; Battilana et al. 2009).

Finally, our study also pays relatively little attention to identity and identification. As previous work highlights, identification and familiarity with the norms of a particular social sphere are important because these factors affect how individuals relate to that social sphere and the conflict they experience (e.g., Lok 2010; Pache and Santos 2013). Identification and familiarity are therefore important for understanding how individuals cognitively cope with tensions between the situational logic and the self (Creed et al. 2010), and how they respond to competing institutional requirements. In our study, we control for our survey participants' familiarity with the logics of the workplaces presented in the vignettes (Pache and Santos 2013) as well as their ethnic backgrounds. However, we do not measure the extent to which these individuals identify with their clan and kinship networks, for which ethnicity is only an indirect proxy.

These limitations aside, we hope that our findings and the perspective developed in this paper encourage new lines of research into the sources and mitigation of favoritism in recruitment and selection. One relevant line of research would be to assess the generalizability of our findings and the value of the paper's perspective by exploring the relations among communal ties, favoritism, and managers' coping strategies in other contexts. For example, although our communal perspective may appear most relevant for collectivist societies, we do not rule out the possibility that similar effects may be observed in individualistic societies as well. We also encourage research that explores whether the observed relationships hold in other types of communities relevant for recruitment, such as professional communities and alumni networks. While we expect the constructs of immediacy and relatedness to be of similar theoretical relevance in other contexts, we also observed that the structural connotations of these constructs may vary. We therefore encourage empirical examinations of the generalizability of our findings to demonstrate considerable sensitivity to how immediacy and relatedness are understood and defined within specific communities.

Another opportunity for new research lies in the observed decoupling of managers' coping mechanisms from their professional judgments. This finding is interesting because researchers often implicitly assume that individuals handle institutional demands in ways that are aligned with their own intentions (e.g., Oliver 1991; Pache and Santos 2013). Our results illustrate that alignment should not be taken for granted, and that managers may play an active role in mediating the relation between communal norms and the appointment of friends and family members. One relevant question is how managers reconcile the apparent tensions between their behaviors and their intentions. Interestingly, several of our Kazakhstani participants reported that they experienced surprisingly little internal conflict between their work and social lives, even when these domains entailed seemingly competing demands. Their comments suggest that individuals who are deeply embedded in collectivist societies may experience institutional demands in a more fluid manner than the "either/or" thinking (Chen and Miller 2011) that tends to characterize academic discussions. We therefore also encourage further examinations of managers' cognitive response strategies when faced with multiple institutional demands as well as studies of how those strategies interrelate with the use of behavioral strategies, such as those observed in this paper. We believe such studies may significantly extend our understanding of how managers handle communal, competitive, and ethical demands in practice.

Acknowledgements The authors thank Marta Geletkanycz, Michael Lounsbury, and seminar participants at WU Vienna, Norwegian School of Economics, and Radboud University Nijmegen for their encouraging comments on early drafts of this paper. The authors also thank the reviewers and editor Harry van Buren III of the Journal of Business Ethics for their constructive suggestions.

\section{Compliance with Ethical Standards}

Conflict of interest The authors declare that they have no conflict of interest.

Ethical Approval At the time of data collection, the authors' field of research lacked an appropriate institutional and/or national research 
committee to which the protocols adopted in the study could be referred. Nevertheless, the authors took care to ensure that the procedures performed in the study were conducted in alignment with international ethical standards, in particular the EU's ESRC framework for research ethics in the social sciences.

Informed Consent Informed consent was obtained verbally from all individual participants included in the study.

Open Access This article is distributed under the terms of the Creative Commons Attribution 4.0 International License (http://creativeco mmons.org/licenses/by/4.0/), which permits unrestricted use, distribution, and reproduction in any medium, provided you give appropriate credit to the original author(s) and the source, provide a link to the Creative Commons license, and indicate if changes were made.

\section{References}

Ahuja, G. (2000). The duality of collaboration: Inducements and opportunities in the formation of interfirm linkages. Strategic Management Journal, 21, 317-343.

Al-Aiban, K. M., \& Pearce, J. L. (1993). The influence of values on management practices: A test in Saudi Arabia and the United States. International Studies of Management \& Organization, $23,35-52$.

Alexander, C. S., \& Becker, H. J. (1978). The use of vignettes in survey research. Public Opinion Quarterly, 42, 93-104.

Almandoz, J. (2012). Arriving at the starting line: The impact of community and financial logics on new banking ventures. Academy of Management Journal, 55, 1381-1406.

Atzmüller, C., \& Steiner, P. M. (2010). Experimental vignette studies in survey research. Methodology: European Journal of Research Methods for the Behavioral and Social Sciences, 6, 128-138.

Baldwin, M. W. (1992). Relational schemas and the processing of social information. Psychological Bulletin, 112, 461-484.

Bastian, B., \& Haslam, N. (2010). Excluded from humanity: The dehumanizing effects of social ostracism. Journal of Experimental Social Psychology, 46(1), 107-113.

Battilana, J., Leca, B., \& Boxenbaum, E. (2009). How actors change institutions: Towards a theory of institutional entrepreneurship. Academy of Management Annals, 3, 65-107.

Battilana., J., \& Dorado, S. (2010). Building sustainable hybrid organizations: The case of commercial microfinance organizations. Academy of Management Journal, 53, 1419-1440.

Begley, T. M., Khatri, N., \& Tsang, E. W. (2010). Networks and cronyism: A social exchange analysis. Asia Pacific Journal of Management, 27, 281-297.

Bian, Y. (1997). Bringing strong ties back in: Indirect ties, network bridges, and job searches in China. American Sociological Review, 62, 366-385.

Biernacki, P., \& Waldorf, D. (1981). Snowball sampling: Problems and techniques of chain referral sampling. Sociological Methods and Research, 10, 141-163.

Boissevain, J. (1966). Patronage in Sicily. Man, 1, 18-33.

Bott, E. (1971). Family and social networks (2nd ed.). London: Tavistock Publications.

Brint, S. (2001). Gemeinschaft revisited: A critique and reconstruction of the community concept. Sociological Theory, 19, 1-23.

Bromley, P., \& Powell, W. W. (2012). From smoke and mirrors to walking the talk: Decoupling in the contemporary world. Academy of Management Annals, 6, 483-530.
Burt, R. S. (1987). Social contagion and innovation: Cohesion versus structural equivalence. American Journal of Sociology, 92(6), 1287-1335.

Cha, S. H. (2000). Korean civil religion and modernity. Social Compass, 47(4), 467-485.

Chatters, L. M., Taylor, R. J., \& Jayakody, R. (1994). Fictive kinship relations in black extended families. Journal of Comparative Family Studies, 25, 297-312.

Chen, C. C., Gaspar, J. P., Friedman, R., Newburry, W., Nippa, M. C., Xin, K., et al. (2015). Paradoxical relationships between cultural norms of particularism and attitudes toward relational favoritism: A cultural reflectivity perspective. Journal of Business Ethics. Advance online publication. https://doi. org/10.1007/s10551-015-2843-6.

Chen, M. J., \& Miller, D. (2011). The relational perspective as a business mindset: Managerial implications for East and West. Academy of Management Perspectives, 25(3), 6-18.

Collins, K. (2006). Clan politics and regime transition in central Asia. Cambridge: Cambridge University Press.

Cox, D., \& Fafchamps, M. (2007). Extended family and kinship networks: Economic insights and evolutionary directions. In T. P. Schultz \& J. A. Strauss (Eds.), Handbook of development economics (pp. 3711-3784). Amsterdam: North-Holland.

Creed, W. D., DeJordy, R., \& Lok, J. (2010). Being the change: Resolving institutional contradiction through identity work. Academy of Management Journal, 53, 1336-1364.

Currie, G., \& Spyridonidis, D. (2016). Interpretation of multiple institutional logics on the ground: Actors' position, their agency and situational constraints in professionalized contexts. Organization studies, 37, 77-97.

DiMaggio, P. (1997). Culture and cognition. Annual Review of Sociology, 23, 263-287.

Dunfee, T. W., \& Warren, D. E. (2001). Is guanxi ethical? A normative analysis of doing business in China. Journal of Business Ethics, 32(3), 191-204.

Ekeh, P. P. (1974). Social exchange theory: The two traditions. Cambridge: Harvard University Press.

Engels, F. (1942). The origin of the family, private property, and the state in the light of the researches of Lewis H. Morgan. New York: International Publishers.

Everitt, B. S. (1993). Cluster analysis (3rd ed.). London: Arnold.

Everitt, B. S., Landau, S., Leese, M., \& Stahl, D. (2011). Cluster analysis (5th ed.). Chichester: Wiley.

Feldman, D. C. (1984). The development and enforcement of group norms. Academy of Management Review, 9(1), 47-53.

Friedland, R., \& Alford, R. R. (1991). Bringing society back in: Symbols, practices, and institutional contradictions. In W. W. Powell \& P. J. DiMaggio (Eds.), The new institutionalism in organizational analysis (pp. 232-263). Chicago: University of Chicago Press.

Fritzsche, D. J., \& Becker, H. (1984). Linking management behavior to ethical philosophy-An empirical investigation. Academy of Management Journal, 27(1), 166-175.

Giorgi, S., \& Palmisano, S. (2017). Sober intoxication: Institutional contradictions and identity work in the everyday life of four religious communities in Italy. Organization Studies, 38(6), $795-819$.

Gordon, A. D. (1999). Classification (2nd ed.). Boca Raton: Chapman and Hall/CRC.

Gould, R. (1995). Insurgent identities: Class, community and protest in Paris from 1848 to the commune. Chicago: University of Chicago Press.

Gouldner, A. W. (1960). The norm of reciprocity: A preliminary statement. American Sociological Review, 25, 161-178.

Granovetter, M. (1995a). The economic sociology of firms and entrepreneurs. In A. Portes (Ed.), The economic 
sociology of immigration (pp. 128-165). New York: Russell Sage Foundation.

Granovetter, M. (1995b). Getting a job: A study of contacts and careers. Chicago: University of Chicago Press.

Granovetter, M. S. (1973). The strength of weak ties. American Journal of Sociology, 78, 1360-1380.

Greene, W. H. (2000). Econometric analysis (4th ed.). Upper Saddle River: Prentice-Hall.

Greenwood, R., Raynard, M., Kodeih, F., Micelotta, E. R., \& Lounsbury, M. (2011). Institutional complexity and organizational responses. Academy of Management Annals, 5, 317-371.

Hardy, C., \& Maguire, S. (2008). Institutional entrepreneurship. In R. Greenwood, C. Oliver, K. Sahlin, \& R. Suddaby (Eds.), The Sage handbook of organizational institutionalism (pp. 198-217). London: Sage.

Holm, A. E., Decreton, B., Nell, P. C., \& Klopf, P. (2017). The dynamic response process to conflicting institutional demands in MNC subsidiaries: An inductive study in the sub-Saharan African E-Commerce Sector. Global Strategy Journal, 7(1), 104-124.

Horak, S. (2016). Join in or opt out? A normative-ethical analysis of affective ties and networks in South Korea. Journal of Business Ethics, 149(1), 207-220.

Horak, S. (2017). The informal dimension of Human Resource Management in Korea: Yongo, recruiting practices, and career progression. International Journal of Human Resource Management, 28(10), 1409-1432.

Hughes, R. (1998). Considering the vignette technique and its application to a study of drug injecting and HIV risk and safer behaviour. Sociology of Health and Illness, 20, 381-400.

Janoff-Bulman, R., \& Leggatt, H. K. (2002). Culture and social obligation: When "shoulds" are perceived as "wants". Journal of Research in Personality, 36, 260-270.

Jones, R. G., \& Stout, T. (2015). Policing nepotism and cronyism without losing the value of social connection. Industrial and Organizational Psychology, 8, 2-12.

Khatri, N., \& Tsang, E. W. (2003). Antecedents and consequences of cronyism in organizations. Journal of Business Ethics, 43(4), 289-303.

Krishnan, P., \& Sciubba, E. (2009). Links and architecture in village networks. The Economic Journal, 119, 917-949.

Ledeneva, A. V. (1998). Russia's economy of favours: Blat, networking and informal exchange. Cambridge: Cambridge University Press.

Liu, C., Eubanks, D. L., \& Chater, N. (2015). The weakness of strong ties: Sampling bias, social ties, and nepotism in family business succession. The Leadership Quarterly, 26, 419-435.

Lok, J. (2010). Institutional logics as identity projects. Academy of Management Journal, 53, 1305-1335.

Lounsbury, M., Ventresca, M., \& Hirsch, P. M. (2003). Social movements, field frames and industry emergence: A cultural-political perspective on US recycling. Socio-Economic Review, 1, 71-104.

Marquis, C., \& Battilana, J. (2009). Acting globally but thinking locally? The enduring influence of local communities on organizations. Research in Organizational Behavior, 29, 283-302.

Marquis, C., \& Lounsbury, M. (2007). Vive la résistance: Competing logics and the consolidation of US community banking. Academy of Management Journal, 50, 799-820.

Marquis, C., Lounsbury, M., \& Greenwood, R. (2011). Introduction: Community as an institutional order and a type of organizing communities and organizations. Research in the Sociology of Organizations, 33, ix-xxvii.

Marsden, P. V., \& Campbell, K. E. (1984). Measuring tie strength. Social Forces, 63, 482-501.

McCarthy, D. J., Puffer, S. M., Dunlap, D. R., \& Jaeger, A. M. (2012). A stakeholder approach to the ethicality of BRIC-firm managers' use of favors. Journal of Business Ethics, 109, 27-38.
Meyer, J. W., \& Rowan, B. (1977). Institutionalized organizations: Formal structure as myth and ceremony. American Journal of Sociology, 83, 340-363.

Minbaeva, D., Hutching, K., \& Thomson, B. (2007). Hybrid human resource management in post-Soviet Kazakhstan. European Journal of International Management, 1, 350-371.

Minbaeva, D., \& Muratbekova-Touron, M. (2013). Clanism: Definition and implications for Human Resource Management. Management International Review, 53, 109-139.

Mozur, P., \& Sang-Hun, C. (2017, February 17). Samsung heir's arrest in South Korea intensifies calls for cleanup. The New York Times. Retrieved from https://www.nytim es.com/2017/02/17/business/samsung-heir-arrested-south -korea.html.

Muir, D. E., \& Weinstein, E. A. (1962). The social debt: An investigation of lower-class and middle-class norms of social obligation. American Sociological Review, 27, 532-539.

Oliver, C. (1991). Strategic responses to institutional processes. Academy of Management Review, 15, 145-179.

Oyserman, D., Sakamoto, I., \& Lauffer, A. (1998). Cultural accommodation: Hybridity and the framing of social obligation. Journal of Personality and Social Psychology, 74, 1606.

Pache, A. C., \& Santos, F. (2010). When worlds collide: The internal dynamics of organizational responses to conflicting institutional demands. Academy of Management Review, 35, $455-476$

Pache, A. C., \& Santos, F. (2013). Embedded in hybrid contexts: How individuals in organizations respond to competing institutional logics. In M. Lounsbury \& E. Boxenbaum (Eds.), Research in the sociology of organizations: Institutional logics in action (Vol. 39, pp. 3-35). Bingley: Emerald Group Publishing.

Pearce, J. L. (2015). Cronyism and nepotism are bad for everyone: The research evidence. Industrial and Organizational Psychology, $8,41-44$.

Pearce, J. L., Branyiczki, I., \& Bigley, G. A. (2000). Insufficient bureaucracy: Trust and commitment in particularistic organizations. Organization Science, 11, 148-162.

Pfeffer, J., \& Salancik, G. R. (1978). The external control of organizations: A resource dependence perspective. New York: Harper and Row.

Pitt-Rivers, J. (1973). The kith and the kin. In J. Goody (Ed.), The character of kinship (pp. 89-105). Cambridge: Cambridge University Press.

Posner, R. A., \& Rasmusen, E. B. (1999). Creating and enforcing norms, with special reference to sanctions. International Review of Law and Economics, 19(3), 369-382.

Prendergast, C., \& Topel, R. H. (1996). Favoritism in organizations. Journal of Political Economy, 104, 958-978.

Raaijmakers, A. G., Vermeulen, P. A., Meeus, M. T., \& Zietsma, C. (2015). I need time! Exploring pathways to compliance under institutional complexity. Academy of Management Journal, 58(1), 85-110.

Rao, H., Monin, P., \& Durand, R. (2003). Institutional change in Toque Ville: Nouvelle cuisine as an identity movement in French gastronomy. American Journal of Sociology, 108, 795-843.

Robertson, C., Crittenden, W., Brady, M., \& Hoffman, J. (2002). Situational ethics across borders: A multicultural examination. Journal of Business Ethics, 38(4), 327-338.

Robertson, C. J., Lamin, A., \& Livanis, G. (2010). Stakeholder perceptions of offshoring and outsourcing: The role of embedded issues. Journal of Business Ethics, 95(2), 167-189.

Rosenzweig, M. R. (1988). Risk, implicit contracts and the family in rural areas of low-income countries. The Economic Journal, 98, $1148-1170$.

Schatz, E. (2004). Modern clan politics: The power of "blood" in Kazakhstan and beyond. Seattle: University of Washington Press. 
Schatz, E. (2005). Reconceptualizing clans: Kinship networks and statehood in Kazakhstan. Nationalities Papers, 33, 231-254.

Schweizer, T., \& White, D. R. (1998). Kinship, networks, and exchange. New York: Cambridge University Press.

Seo, M. G., \& Creed, W. D. (2002). Institutional contradictions, praxis, and institutional change: A dialectical perspective. Academy of Management Review, 27, 222-247.

Shane, S., \& Cable, D. (2002). Network ties, reputation, and the financing of new ventures. Management Science, 48, 364-381.

Skilton, P. F. (2008). Similarity, familiarity and access to elite work in Hollywood: Employer and employee characteristics in breakthrough employment. Human Relations, 61, 1743-1773.

Smets, M., Jarzabkowski, P., Burke, G. T., \& Spee, P. (2015). Reinsurance trading in Lloyd's of London: Balancing conflictingyet-complementary logics in practice. Academy of Management Journal, 58(3), 932-970.

Stahl, G., Björkman, I., Farndale, E., Morris, S. S., Paauwe, J., Stiles, P., et al. (2012). Six principles of effective global talent management. Sloan Management Review, 53, 25-42.

Sudarkasa, N. (1998). Interpreting the African heritage in Afro-American family organization. In K. V. Hansen \& A. I. Garey (Eds.), Families in the U.S.: Kinship and domestic politics (pp. 91-104). Philadelphia: Temple University Press.

Tanure, B., \& Duarte, R. G. (2005). Leveraging competitiveness upon national cultural traits: The management of people in Brazilian companies. International Journal of Human Resource Management, 76(12), 2201-2217.

Thornton, P. (2004). Markets from culture: Institutional logics and organizational decisions in higher education publishing. Stanford: Stanford University Press.

Thornton, P. H. (2001). Personal versus market logics of control: A historically contingent theory of the risk of acquisition. Organization Science, 12, 294-311.

Thornton, P. H., \& Ocasio, W. (1999). Institutional logics and the historical contingency of power in organizations: Executive succession in the higher education publishing industry, 1958-1990. American Journal of Sociology, 105(3), 801-843.

Thornton, P. H., \& Ocasio, W. (2008). Institutional logics. In R. Greenwood, C. Oliver, K. Sahlin, \& R. Suddaby (Eds.), The Sage handbook of organizational institutionalism (pp. 99-129). London: Sage.

Thornton, P. H., Ocasio, W., \& Lounsbury, M. (2012). The institutional logics perspective: A new approach to culture, structure, and process. Oxford: Oxford University Press.

Triandis, H. C. (1995). Individualism and collectivism: New directions in social psychology. Boulder: Westview Press.

Trongmateerut, P., \& Sweeney, J. T. (2013). The influence of subjective norms on whistle-blowing: A cross-cultural investigation. Journal of Business Ethics, 112(3), 437-451.
Tsang, E. W. (1998). Can guanxi be a source of sustained competitive advantage for doing business in China? Academy of Management Executive, 12(2), 64-73.

Tung, R. L., \& Worm, V. (2001). Network capitalism: The role of human resources in penetrating the China market. International Journal of Human Resource Management, 12(4), 517-534.

Wade, R. (1988). Village republics: Economic conditions for collective action in South India. Cambridge: Cambridge University Press.

Wallander, L. (2009). 25 Years of factorial surveys in sociology: A review. Social Science Research, 38, 505-520.

Warren, D. E., Dunfee, T. W., \& Li, N. (2004). Social exchange in China: The double-edged sword of guanxi. Journal of Business Ethics, 55, 355-372.

Wasko, M., \& Faraj, S. (2000). It is what one does": Why people participate and help others in electronic communities of practice. The Journal of Strategic Information Systems, 9, 155-173.

Wated, G., \& Sanchez, J. I. (2015). Managerial tolerance of nepotism: The effects of individualism-collectivism in a Latin American context. Journal of Business Ethics, 130, 45-57.

Weber, J. (1992). Scenarios in business ethics research: Review, critical assessment, and recommendations. Business Ethics Quarterly, $2,137-160$

Weber, K., \& Glynn, M. A. (2006). Making sense with institutions: Context, thought and action in Karl Weick's theory. Organization Studies, 27(11), 1639-1660.

Wellman, B., \& Wortley, S. (1990). Different strokes from different folks: Community ties and social support. American journal of Sociology, 96, 558-588.

Westphal, J. D., \& Zajac, E. J. (1997). Defections from the inner circle: Social exchange, reciprocity, and the diffusion of board independence in US corporations. Administrative Science Quarterly, $42,161-183$.

White, D. R. (2011). Kinship, class, and community. In J. Scott \& P. J. Carrington (Eds.), The SAGE handbook of social network analysis (pp. 129-147). London: Sage.

Wiessner, P. (2005). Norm enforcement among the Ju/'hoansi Bushmen. Human Nature, 16(2), 115-145.

Williams, R. (2000). A note on robust variance estimation for clustercorrelated data. Biometrics, 56, 645-646.

Publisher's Note Springer Nature remains neutral with regard to jurisdictional claims in published maps and institutional affiliations. 